\title{
Cabazitaxel for Metastatic Castrate-Resistant Prostate Cancer: A Case Presentation
}

\author{
Simon B. Zeichner ${ }^{1}$, Michael Cusnir ${ }^{2}$ \& Michael Francavilla ${ }^{3}$ \\ ${ }^{1}$ Internal Medicine, Mount Sinai Medical Center, Miami Beach, USA \\ ${ }^{2}$ Hematology and Oncology, Comprehensive Cancer Center, Miami Beach, USA \\ ${ }^{3}$ Radiology, Mount Sinai Medical Center, Miami Beach, USA \\ Correspondence: Simon Zeichner D.O., Mount Sinai Medical Center, 4300 Alton Road, Miami Beach, FL 33140, \\ USA. Tel: 1-845-417-1969. E-mail: simonzeichner@gmail.com
}

Received: March 5, 2012 Accepted: March 19, 2012 Online Published: May 1, 2012

doi:10.5539/cco.v1n1p118 URL: http://dx.doi.org/10.5539/cco.v1n1p118

No funding was provided for this case presentation.

The authors declare that they have no competing interests.

\begin{abstract}
Introduction: Although cabazitaxel was proven efficacious by a large Phase III trial and was approved for second-line treatment of metastatic castrate-resistant prostate cancer, case reports describing its efficacy and safety are lacking in the literature. More data is needed describing castrate-resistant prostate cancer cases that progress with $1^{\text {st }}$ line therapy. Case Presentation: A 78-year old Hispanic male presented to the clinic in July 2011 with a 3-month history of worsening left knee pain, generalized fatigue, and a 5.4 kilogram weight loss. His past medical history was significant for metastatic prostate cancer and his laboratory results were notable for an alkaline phosphatase of $221 \mathrm{U} / \mathrm{L}$, a prostate specific antigen of $837.7 \mathrm{ng} / \mathrm{ml}$, and a creatinine of 1.94 . Discussion: Metastatic prostate cancer results from the combination of lymphatic, blood, or contiguous local spread. Cabazitaxel is a novel semi-synthetic tubulin binding taxane that uses a precursor molecule extracted from yew tree needles. In the phase III TROPIC study, CRPC patients previously taking docetaxel had a significant increase in overall survival with cabazitaxel compared with mitoxantrone ( 15.1 vs. 12.7 months, $\mathrm{p}<0.001)$. Conclusion: Cabazitaxel appears to be safe chemotherapeutic agent and has moved to the forefront in our armamentarium for the treatment in castrate-resistant prostate cancer.
\end{abstract}

Keywords: castrate resistant prostate cancer, cabazitaxel

\section{Introduction}

According to the American Cancer Society, 240,890 new cases of prostate cancer will be diagnosed in 2011 and 33,720 men will die from their disease (American, 2011). Although it's the second most common cancer in men, prostate cancer is one of the most heterogeneous in terms of aggressiveness. Most men will achieve disease control with watchful waiting, surgical prostatectomy, localized prostate radiation, or some combination of the three. For men with aggressive cancers who develop metastatic disease, first line treatment involves hormone therapy. Despite controlling the disease for an extended amount of time, all men will eventually progress to the point where their tumors no longer respond to hormone manipulation and are deemed castrate-resistant. Treatment with systemic chemotherapy remains the only viable option for patients with metastatic castrate-resistant prostate cancer (CRPC). Chemotherapy for this disease has come a long way over the past twenty years. Up until the mid-1990's, CRPC had a median survival of 12 months and was treated with palliative intent as no regimens were found to be both effective and tolerable. Mitoxantrone with prednisone became the standard of care in 1996 after Tannock et al. showed that it caused a reduction in patient's bone pain and PSA level (Tannock, de Wit, \& Berry, 2004). In 2004, the TAX327 trial and a Southwest Oncology Group study found a significant survival advantage of docetaxel compared to mitoxantrone (Petrylak, Tangen, \& Hussain 2006; Smith, Dunn, Strawderman, \& Pienta, 1998). As a result of these studies, docetaxel became the first line option for CRPC. There remained limited second line options for patients who progressed on docetaxel up until the recent phase III trials and subsequent United States Federal Drug Administration approval of three new 
agents. Sipuleucel-T, an autologous cellular vaccine, was assessed in the phase III IMPACT trial and found to significantly prolong overall survival when compared to placebo (Jevtana, 2012). Abiraterone acetate, an anti-androgen, was assessed in a phase III study, COU-AA-301, in which it was found to have a significant increase in overall survival when compared with placebo (de Bono, Logothetis, \& Fizazi, 2010). Cabazitaxel, a novel taxane, was assessed in the phase III TROPIC study, in which it was found that cabazitaxel/prednisone had a significant survival advantage over mitoxantrone/prednisone in $755 \mathrm{men}$ with docetaxel-refractory metastatic CRPC (de Bono, Oudard, \& Ozguroglu, 2010). Based on this study, cabazitaxel became approved by the United States Federal Drug Administration in June 2010 and by the European Medicine Agency in January 2011 for treatment of CRPC in patients already treated with docetaxel (FDA, 2010).

We present a case of a man with metastatic castrate-resistant prostate cancer and chronic kidney disease, who was previously on taxane-based therapy, and achieved a great response with cabazitaxel without an adverse effect on hematologic or renal function.

\section{Case Presentation}

A 78-year old Hispanic male presented to the clinic in July 2011 with a 3-month history of worsening left knee pain, generalized fatigue, and a 5.4 kilogram weight loss. His past medical history was significant for metastatic prostate cancer, colon cancer, chemotherapy-induced anemia, essential hypertension, and chronic kidney disease stage III. His past surgical history was significant for a colon resection and mitral valve replacement both in 2002. His medications included oxycodone, clopidogrel, metoprolol, furosemide, and a calcium supplement. He was a non-smoker and had a family history significant for a sister, father, and son who had all died of lung cancer. On physical exam, he was afebrile with stable vital signs. He was $168 \mathrm{~cm}$ tall and weighed $60.8 \mathrm{~kg}$. Physical exam revealed right knee swelling with no palpable lymphadenopathy. Laboratory results were notable for white blood cell count of $9.9 \times 10^{3} / \mathrm{ul}$ (Absolute neutrophil count 7722 microliter, hemoglobin of $9.7 \mathrm{~g} / \mathrm{dL}$, hematocrit of $29.5 \mathrm{~g} / \mathrm{dL}$, platelet count of $187 \times 10^{3} / \mathrm{uL}$, asparate aminotransferase 22 , alanine aminotransferase 11 , total bilirubin $0.4 \mathrm{mg} / \mathrm{dL}$, alkaline phosphatase of $221 \mathrm{U} / \mathrm{L}$, prostate specific antigen (PSA) of $837.7 \mathrm{ng} / \mathrm{ml}$, and creatinine $1.93 \mathrm{mg} / \mathrm{dL}$ (creatinine clearance $27 \mathrm{ml} / \mathrm{min}$ ).

The patient was initially diagnosed with prostate cancer in 1997 and was treated with localized radiation. Five years later, he was diagnosed with early stage sigmoid colon adenocarcinoma and was treated with local surgical resection without adjuvant chemotherapy. The patient was symptom free until May of 2007, in which he began complaining of diffuse bone pain. On a subsequent pelvic x-ray, he was found to have blastic bony lesions in the ilium, pubis, and femur that were highly suspicious for metastasis. The patient was placed on ketoconazole for 2 months and treated with a course of palliative external beam radiotherapy to the left hemi-pelvis at a dose of $3,000 \mathrm{cGy}$ in 10 fractions over two weeks. The patient achieved a complete pain response and his PSA remained stable at $200 \mathrm{ng} / \mathrm{ml}$ for over a year. In September 2008, the patient's PSA level had risen to $467 \mathrm{ng} / \mathrm{ml}$, and as a result, was started on diethylstilbestrol (DES). However, patient developed severe gynecomastia secondary to the hormone therapy and was treated with prophylactic bilateral breast irradiation at a dose of $1200 \mathrm{cGY}$ in 3 fractions over three days. He remained on DES for several months and achieved a nadir PSA of $180 \mathrm{ng} / \mathrm{ml}$. However, in June of 2009, the patient came into the clinic complaining of worsening pain and a PSA greater than $1,000 \mathrm{ng} / \mathrm{ml}$. The patient was started on paclitaxel at a dose of $75 \mathrm{mg} / \mathrm{m}^{2}$. He achieved a complete pain response over the next several months and a nadir PSA of 26.4. After finishing his course of paclitaxel in April of 2010, the patient was placed on leuprolide acetate for 6 months for maintenance therapy. In November of 2010, the patient was restarted on paclitaxel and prednisone due to a rising PSA of $202 \mathrm{ng} / \mathrm{ml}$ and severe lower back pain. The patient achieved disease stability for several months, but a bone scinitography in January 2011 revealed an overall worsening of osseous metastatic disease with new foci seen in bilateral shoulders, sacrum, thoracolumbar spine, right femur, and anterior left first rib (Figure 1). Repeat bone scinitography in March 2011 showed disease stability and the patient remained on chemotherapy until May 2011. 


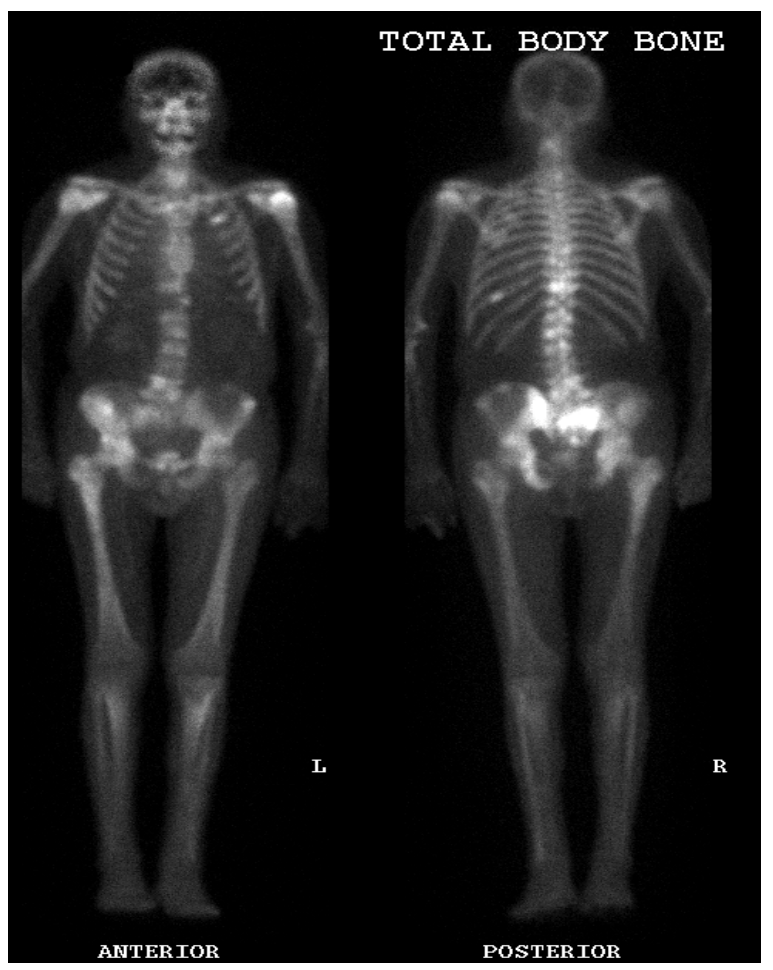

Figure 1. Bone scinitography in January 2011

Reveals an osseous metastatic disease with new foci seen in bilateral shoulders, sacrum, thoracolumbar spine, right femur, and anterior left first rib

After patient presentation in July 2011, he was started on a new chemotherapeutic regimen includingcabazitaxel $25 \mathrm{mg} / \mathrm{m}^{2}$ IV (day 1 ) with prednisone $10 \mathrm{mg}$ orally (days 1-21). He was pre-medicated with ondansetron for the prevention of chemotherapy induced nausea and was started on supplementary filgrastim $5 \mathrm{mcg} / \mathrm{kg} / \mathrm{day}$ every three weeks for the prevention of chemotherapy-induced neutropenia. Patient complete blood counts with differential were checked weekly during the first cycle and at the start of each subsequent treatment cycle. Renal and liver function testing were monitored every three weeks during treatment and neurological and gastrointestinal toxicities were monitored throughout treatment.

Upon a follow-up visit in late August 2011, after receiving 2 cycles of cabazitaxel, the patient's PSA had decreased from $837.7 \mathrm{ng} / \mathrm{ml}$ to a level of $315 \mathrm{ng} / \mathrm{ml}$ and had a complete pain response in which he no longer needed pain medication to perform his activities of daily living. The patient only reported grade 1 diarrhea after the first cycle of chemotherapy, with no other toxicities noted. At a follow up visit to the clinic in November 2011, after receiving four cycles of cabazitaxel, the patient reported no pain, his weight remained stable, had a stable absolute neutrophil count, and his PSA was found to be decreased to a level of $278.8 \mathrm{ng} / \mathrm{ml}$. In January 2012, six months and six cycles after the start of initial cabazitaxel therapy, the patient appeared to be progressing with a PSA of $446.7 \mathrm{ng} / \mathrm{ml}$. However, he continued to be pain and fatigue free with stable absolute neutrophil count (ANC 9292microliter), stable anemia (hemoglobin 10.6g/dL hematocrit 31.9), normal liver function tests (asparate aminotransferase $18 \mathrm{U} / \mathrm{L}$, alanine aminotransferase $11 \mathrm{U} / \mathrm{L}$, total bilirubin $0.4 \mathrm{mg} / \mathrm{dL}$, alkaline phosphatase $81 \mathrm{U} / \mathrm{L})$ and a stable creatinine $(1.77 \mathrm{mg} / \mathrm{dL})$.

\section{Discussion}

Although cabazitaxel was proven efficacious by a large Phase III trial and was approved for second-line treatment of metastatic castrate-resistant prostate cancer, case reports describing its efficacy and safety (especially in renal dysfunction) are lacking in the literature. Only one recent case report from the Dana Farber Cancer Institute could be found in the literature describing the use of this chemotherapeutic agent in individual patients (Guancial \& Taplin, 2010). More data is needed describing CRPC cases that progress with $1^{\text {st }}$ line docetaxel therapy and are started on second line agents. In order to better characterize the efficacy of cabazitaxel in extending overall survival, it will be important to understand the clinical tendencies of metastatic prostate cancer and the mechanism of action of cabazitaxel in CRPC. It will also be vital to understand patient length of 
response to treatment, previously tried agents, time of disease progression, and overall adverse effects.

Metastatic prostate cancer results from the combination of lymphatic, blood, or contiguous local spread (Tannock, Osoba, \& Stockler, 1996). Most often metastasizing to bone, manifestations of metastatic disease can range from anemia to bone pain to urinary retention. Metastatic disease can be detected with the use of positron emission tomography, magnetic resonance imaging, or radionuclide bone scan. As a result of the difficulty of monitoring response with systemic chemotherapy in CRPC, surrogate markers have been used as indicators of clinical benefit, which include a decline in serum PSA, improvement in bone pain, analgesic consumption, and quality of life (Armstrong, Garrett-Mayer, \& Ou Yang 2006; Sartor, 2011; Scher, Kelly, \& Zhang, 1999; Scher, Warren, \& Heller, 2011; Smith, Dunn, Strawderman, \& Pienta, 1998).

Cabazitaxel is a novel semi-synthetic tubulin binding taxane that uses a precursor molecule extracted from yew tree needles (Paller \& Antonarakis, 2011). By binding to tubulin, cabazitaxel inhibits microtubule depolymerization and cell division resulting in cell cycle arrest. Cabazitaxel has demonstrated superior in vitro cytotoxicity compared to docetaxel in several murine and human cancer cell lines (Mahon, Henshall, Sutherland, \& Horvath, 2011). Additionally, several preclinical models have demonstrated superior blood-brain barrier penetration of cabazitaxel when compared to $1^{\text {st }}$ and $2^{\text {nd }}$ generation taxanes, paclitaxel and docetaxel, respectively (Mita, Denis, \& Rowinsky, 2009). As opposed to a docetaxel molecule, cabazitaxel has an extra methyl group replacing a hydroxyl group, which gives the molecule its poor affinity for P-glycoprotein, an ATP-dependent drug efflux pump (Bradshaw \& Arceci, 1998). Cancer cells that express P-glycoprotein become resistant to taxanes like docetaxel through the over expression of multi-drug resistant gene 1 (MDR1) (Borst, Evers, Kool, \& Wijnholds, 2000; Rowinsky, Smith, \& Wang, 1998).

In the phase III TROPIC study, CRPC patients previously taking docetaxel had a significant increase in overall survival with cabazitaxel compared with mitoxantrone (15.1 vs. 12.7 months, $p<0.001)$ (7). The survival benefit extended across patients of Eastern Cooperative Oncology Group performance status (ECOG 0-2), measurable disease (absent or present), number of previous chemotherapeutic agents ( 1 or $\geq 2$ ), age (greater than or less than $65)$, and pain (baseline, absent, or present). Progression free survival ( 2.8 vs. 1.4 months $\mathrm{p}<0.0001)$ and median time to PSA progression (6.1 vs. 3.1 months, $\mathrm{p}<0.001$ ) favored cabazitaxel. There was concern regarding $\geq$ grade 3 toxicity noted in $82 \%$ of the cabazitaxel patients. As a result of this observation, the FDA advised the use of primary prophylaxis with granulocyte-colony stimulating factors (G-CSF) in those patients considered to be high risk (US, 2012). Practitioners were advised against its use if patient neutrophil count was $\leq 1500 \mathrm{cells} / \mathrm{mm}^{3}$. For prolonged grade 3 or 4 neutropenia despite G-CSF, practitioners were advised to delay treatment until patient neutrophil count is $>1500$ cells $/ \mathrm{mm}^{3}$ and to then reduce patient dose to $20 \mathrm{mg} / \mathrm{m}^{2}$. For grade 3 or higher diarrhea or persisting diarrhea despite appropriate medication and fluid and electrolyte replacement, practitioners were advised to delay treatment until improvement and reduce the dose to $20 \mathrm{mg} / \mathrm{m}^{2}$.

Cabazitaxel is $89 \%$ to $92 \%$ protein bound and is metabolized primarily by the liver via the CYP3A4 and $3 \mathrm{~A} 5$ P-450 enzymes (de Bono, 2010; Mita, 2009). Its half-life is approximately 95 hours and is excreted primarily in the feces. Adverse effects in clinical trials showed raised concerns regarding the use of cabazitaxel in patients with impaired liver and renal function. The FDA advised against the use of this agent for patients with elevated bilirubin or if AST and/or ALT were $\geq 1.5$ times the upper limit of normal. Additionally, practitioners were advised to use the agent with caution in patients with a creatinine clearance $<30 \mathrm{~mL} / \mathrm{min}$.

Cabazitaxel is currently being tested in a non-inferiority phase III study comparing the use of a $20 \mathrm{mg} / \mathrm{m}^{2}$ vs. $25 \mathrm{mg} / \mathrm{m}^{2}$ for CRPC (United, 2012). Another phase III study is comparing the use of cabazitaxel at both previously mentioned doses versus docetaxel for first line treatment in CRPC. Results of both studies are expected in late 2017.

\section{Conclusion}

Cabazitaxel appears to be safe chemotherapeutic agent and has moved to the forefront in our armamentarium for the treatment in castrate-resistant prostate cancer. Although once thought to have a very limited overall survival, advanced prostate cancer patients treated with new agents, such as cabazitaxel, are living longer pain free lives. Further studies will need to be conducted to determine ideal doses and combinations of systemic chemotherapy that maximize responses and limit overall adverse effects. Future studies will hopefully also shed light on possible genetic markers that identify patients more likely to respond to specific chemotherapy treatments. Metastatic castrate resistant prostate cancer treatment has made great strides over the past twenty years and with additional research, there will hopefully be further increases in overall survival. 


\section{Acknowledgements}

No contributions were made towards this case presentation.

SZ wrote case presentation, gathered patient data, and organized the case for submission. MC provided case and made corrections on case presentation. MF provided the radiographic image.

Written informed consent was obtained from the patient for publication of this manuscript and accompanying images. A copy of the written consent is available for review by the Editor-In-Chief of this journal.

\section{References}

American Cancer Society. (2011). Prostate Cancer: What are the key statistics about prostate cancer? Retrieved from http://www.cancer.org/Cancer/ProstateCancer/DetailedGuide/prostate-cancer-key-statistics

Armstrong, A. J., Garrett-Mayer, E., Ou Yang, Y. C., et al. (2007).Prostate-specific antigen and pain surrogacy analysis in metastatic hormone-refractory prostate cancer. J Clin Oncol, 25, 3965.

Borst, P., Evers, R., Kool, M., \& Wijnholds, J. (2000). A family of drug transporters: the multidrug resistance-associated proteins. J Natl Cancer Inst, 92(16), 1295-1302. http://dx.doi.org/10.1093/jnci/92.16. 1295

Bradshaw, D. M., \& Arceci, R. J. (1998). Clinical relevance of transmembrane drug efflux as a mechanism of multidrug resistance. J Clin Oncol, 16(11), 3674-3690.

de Bono, J., Logothetis, C., Fizazi, K., et al. (2010). Abiraterone acetate (AA) plus low dose prednisone (P) improves overall survival (OS) in patients (pts) with metastatic castration-resistant prostate cancer (mCRPC) who have progressed after docetaxel-based chemotherapy (chemo): results of COU-AA-301. A randomized double-blind placebo-controlled phase 3 study. (Abstract LBA5). Ann Oncol.

de Bono, J., Oudard, S., Ozguroglu, M., et al. (2010). Prednisone plus cabazitaxel or mitoxantrone for metastatic castration-resistant prostate cancer progressing after docetaxel treatment: a randomized open-label trial. Lancet, 376, 1147-54. http://dx.doi.org/10.1016/S0140-6736(10)61389-X

FDA Center for Drug Evaluation and Research Approval. (2010). Jevtana. Retrieved from http://www.accessdata.fda.gov/drugsatfda_docs/nda/2010/201023s000Approv.pdf.

Guancial, E. A., \& Taplin, M. E. (2011). Case Report: Responses to Cabazitaxel in Metastatic Castration-Resistant Prostate Cancer after Extensive Docetaxel Treatment. Clin. Genitourin Cancer, 9(2), 130-132. http://dx.doi.org/10.1016/j.clgc.2011.06.001

Jordan, M. A., \& Wilson, L. (2004). Microtubules as a target for anticancer drugs. Nat Rev Cancer, 4(4), 253-265. http://dx.doi.org/10.1038/nrc1317

Kantoff, P., Higano, C., Shore, N., et al. (2010). Sipuleucel-T immunotherapy for castration-resistant prostate cancer. $N$ Engl J Med, 363, 411-22.

Kim, S. J., \& Kim, S. I. (2011). Current treatment strategies for castration-resistant prostate cancer. Korean $J$ Urol, 52(3), 157-65. http://dx.doi.org/10.4111/kju.2011.52.3.157

Kao, S. C., Hovey, E., Marx, G. (2011). Second-line therapy for castrate-resistant prostate cancer: a literature review. Asia Pac J Clin Oncol, 7(3), 212-23. http://dx.doi.org/10.1111/j.1743-7563.2011.01421.x.

Mahon, K. L., Henshall, S. M., Sutherland, R. L., \& Horvath, L. G. (2011). Pathways of chemotherapy resistance in castration-resistant prostate cancer. Endocr Relat Cancer, 18(4), R103-23. http://dx.doi.org/10.1530/ERC $-10-0343$

Mita, A. C., Denis, L. J., Rowinsky, E. K., et al. (2009). Phase I and pharmacokinetic study of XRP6258 (RPR 116258A), a novel taxane, administered as a 1-hour infusion every 3 weeks in patients with advanced solid tumors. Clin Cancer Res, 15(2), 723-730. http://dx.doi.org/10.1158/1078-0432

Mottet, N., Bellmunt, J., Bolla, M., et al. (2011). Guidelines on prostate cancer. Part II: Treatment of advanced, relapsing, and castration-resistant prostate cancer. Actas Urol Esp, 35(10), 565-579. http://dx.doi.org/10. 1016/j.acuroe.2012.01.001

Pal, S. K., Twardowski, P., \&Sartor, O. (2010). Critical appraisal of cabazitaxel in the management of advanced prostate cancer. Clin Interv Aging, 3(5), 395-402. Retrieved from http://dx.doi.org/10.2147/CIA.S14570

Paller, C. J., \& Antonarakis, E. S. (2011). Cabazitaxel: a novel second-line treatment for metastatic castration-resistant prostate cancer. Drug Des Devel Ther, 5, 117-24. http://dx.doi.org/10.2147/DDDT.S13029 
Petrylak, D. P., Ankerst, D. P., Jiang, C. S., et al. (2006). Evaluation of prostate-specific antigen declines for surrogacy in patients treated on SWOG 99-16. J Natl Cancer Inst, 98, 516.http://dx.doi.org/10.1093/jnci/ djj 129

Petrylak, D. P., Tangen, C. M., Hussain, M. H., et al. (2004). Docetaxel and estramustine compared with mitoxantrone and prednisone for advanced refractory prostate cancer. $N$ Engl J Med, 351(15), 1513-1520.

Rowinsky, E. K., Smith, L., Wang, Y. M., et al. (1998). Phase I and pharmacokinetic study of paclitaxel in combination with biricodar, a novel agent that reverses multidrug resistance conferred by over expression of both MDR1 and MRP. J Clin Oncol, 16(9), 2964-2976.

Sartor, A. O. (2011). Progression of metastatic castrate-resistant prostate cancer: impact of therapeutic intervention in the post-docetaxel space. J Hematol Oncol, 4, 18. http://dx.doi.org/10.1186/1756-8722-4-18

Scher, H. I., Kelly, W. M., Zhang, Z. F., et al. (1999). Post-therapy serum prostate-specific antigen level and survival in patients with androgen-independent prostate cancer. $J$ Natl Cancer Inst, 91, 244.http://dx.doi.org/10.1093/jnci/91.3.244

Scher, H. I., Warren, M., \& Heller, G. (2007). The association between measures of progression and survival in castrate-metastatic prostate cancer. Clin Cancer Res, 13, 1488. http://dx.doi.org/10.1158/1078-0432.CCR06-1885

Small, E. J., McMillan, A., Meyer, M., et al. (2001). Serum prostate-specific antigen decline as a marker of clinical outcome in hormone-refractory prostate cancer patients: association with progression-free survival, pain end points, and survival. J Clin Oncol, 19, 1304.

Smith, D. C., Dunn, R. L., Strawderman, M. S., \& Pienta, K. J. (1998). Change in serum prostate-specific antigen as a marker of response to cytotoxic therapy for hormone-refractory prostate cancer. $J$ Clin Oncol, $16,1835$.

Tannock, I. F., de Wit, R., Berry, W. R., et al. (2004). Docetaxel plus prednisone or mitoxantrone plus prednisone for advanced prostate cancer. N Engl J Med, 351(15), 1502-1512.

Tannock, I. F., Osoba, D., Stockler, M. R., et al. (1996). Chemotherapy with mitoxantrone plus prednisone or prednisone alone for symptomatic hormone-resistant prostate cancer: a Canadian randomized trial with palliative end points. J Clin Oncol, 14(6), 1756-1764.

Terris, M., Qureshi, S., Schwartz, B., et al. (2011). Metastatic and Advanced Prostate Cancer. Retrieved from http://emedicine.medscape.com/article/454114-overview

Tsao, C. K., Seng, S., Oh, W. K., \& Galsky, M. D. (2011). Clinical development of cabazitaxel for the treatment of castration-resistant prostate cancer. Clin Med Insights Oncol, 5, 163-9. http://dx.doi.org/10.4137/CMO. S6566

United States National Institute of Health, Current clinical trials: Cabazitaxel. (2012). Retrieved from http://clinicaltrials.gov/ct2/results?term=cabazitaxel)

US National Library of Medicine. (2012). Jevtana (cabazitaxel) injection: US FDA-approved manufacturer's package insert. Retrieved from www.dailymed.nlm.nih.gov 